\title{
INTEGRATED PLATFORM FOR THE ANALYSIS AND DESIGN OF TALL BUILDINGS FOR WIND LOADS
}

\begin{abstract}
Mihail IANCOVICI - Associate Professor, PhD, Technical University of Civil Engineering, Faculty of Civil Engineering, e-mail: mihail.iancovici@utcb.ro

Abstract: The Romanian, as well as other wind design codes for building structures, provides with limited degree of accuracy, the aerodynamic loads distribution on buildings up to 200 meters tall in an equivalent static approach (ESWL). For tall wind-sensitive building structures, especially for those with irregular shapes, most of the codes or standards recommend for design to use pressure data recorded in the wind tunnel. The ESWL approach is however used as reference estimation and structural first phase design. Advances on experimental and computational capabilities, led in the past decade to a significant development of time-domain analysis framework, both for seismic and wind loads. While the major outcome for earthquake engineering practitioners is to select appropriate design input ground motions at a particular site, the wind engineering practitioners are facing numerical difficulties to handle large wind loading durations, especially dealing with nonlinearinduced effects.

The paper presents a real-time integrated framework for the analysis and design of tall buildings to wind loads, based on the time-domain analysis tool, as a prerequisite for higher level modules as vulnerability, risk and loss estimation, and optimization analyses.
\end{abstract}

Keywords: wind load, tall building, wind tunnel, dynamic response, design

\section{Introduction}

Several important office tall buildings were built as an effect of increasingly business demand in Romania (Figure 1, public data). The trend of bringing modern built infrastructure in the actual building stock is in progress. The major concern for structural designers in Bucharest is the effects induced by strong ground motions on soft soil conditions, repeatedly generated from Vrancea seismic source [1]. For seismic applications, various proposals were made in the recent years towards guidelines to select appropriate design acceleration input ground motions at a particular site and implementing a time-domain approach for the seismic response analysis and design [2], [3], [4], [5] and [6].
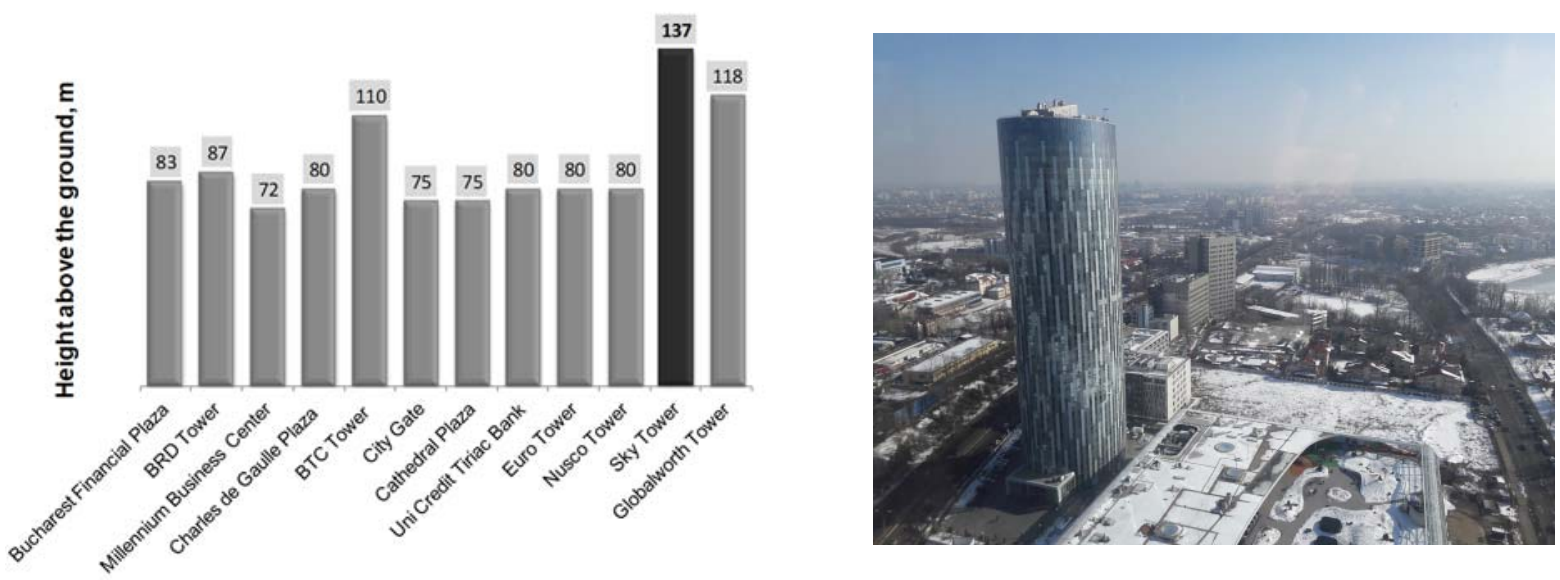

Fig.1 - Tall buildings in Bucharest after 1990 (left figure) and the Sky Tower (RC structure; right figure)

The wind-induced effects are of equally concern for such wind-sensitive structures- as tall buildings are, from the point-of-view of adequacy of design with the comfort, safety of claddings and structural systems criteria. 
The Performance-Based Design (PBD) concept and framework, initially proposed for seismic applications, is widely recognized as a necessary tool for wind engineering applications too. Thus, unified analysis procedures in a global seismic- and wind- PBD framework are possible primarily due to the development of numerically effective solvers for the dynamic response analysis. Structural wind-induced damage evaluation and loss estimation can be performed now by straightforward using the available wind-induced pressure time-histories and the Nonlinear Dynamic Analysis (NDA) tool [7]. The recently issued Pre-standard for Performance-based Wind Design [8], provides the general guideline for integrated procedures to be used for seismic and wind applications.

The current structural analysis and design for wind loads is based on the Equivalent Static Wind Loads (ESWL) approach. The Romanian Wind Design Code CR1-1-4/2012 (EC1 format, [9]) as well as myriad national codes or standards, provides with limited degree of accuracy, the aerodynamic loads distribution on buildings up to 200 meters tall. The main wind design codes primarily provide estimates for the along-wind component, quantified based on quasi-steady and strip theories and the Gust Factor approach. For the across- and torque- induced effects however, only very few national codes provide similar empirical relationships [10].

For tall, wind-sensitive building structures with irregular shapes, most codes or standards recommend that such structures to be designed using pressure data recorded in the wind tunnel (WT) facilities. The ESWL approach is however used as reference estimation and structural preliminary design phase.

Useful comparisons regarding the wind loads calculation and response evaluation for tall buildings based on main national code requirements (i.e. American Society of Civil Engineers' Minimum Design Loads for Buildings and Other Structures (ASCE), Australian and New Zealand Standard (AS/NZ), Architectural Institute of Japan Recommendations (AIJ), China National Standard (CNS), National Building Code of Canada (NBCC), European Standard (EC1), International Organization for Standardization (ISO) and the Indian Wind Code (IWC)), are provided by Kwon and Kareem (2013, [10]). Comprehensive studies based on the above-mentioned code provisions and a databaseenabled procedure- provided through the NatHaz Aerodynamic Loads Database-NALD [11] obtained on tall generic buildings, revealed a large scattering of results, significantly influenced by the wind speed profile, averaging time, turbulence profile and pressure/force coefficients.

On the other hand, due to their inherent limitations, the wind design codes generally provide overestimates compared with those obtained from wind tunnel measurements. Kijewski and Kareem (1998) conducted extensive studies on the structural response based on several wind codes provisions and WT measurements [12]. The results indicate the validity of empirical relationships used in standards and the relative scattering and conservativeness of code-based response parameters.

According to the National Institute of Standards and Technology (NIST) Report- Section E3 [13], "the wind loads used for the WTC towers, which governed the structural design of the external columns and provided the baseline capacity of the structures to withstand abnormal events such as major fires or impact damage, significantly exceeded the requirements of the New York City Building Code and other building codes of the day that were reviewed by NIST. Two sets of wind load estimates for the towers obtained by independent commercial consultants in 2002, however, differed by as much as 40 percent".

While the frequency-domain approach for the estimation of wind effects on structures was developed and extensively used since more than a half century ago, the full capabilities of timedomain approach and associated random vibration theory tools are not yet available in a standardized framework.

Various commercial structural analysis software platforms are nowadays able to perform automated analysis and design using the ESWL approach, based on national code requirements. 
None of them are however tailored to implement available simultaneous pressure measurements for similar automated time-domain analysis and design, despite more affordable access (equipment and costs) to experimental facilities. As a preparatory stage for such a development, wind tunnel testing methodologies were proposed to be used in conjunction by wind consultants and structural engineering practitioners [14].

The Database Assisted Design (DAD) concept for wind loads was initially developed for lowrise buildings by Whalen et al. (2000) [15] and successfully extended later to tall, flexible buildings, through a remarkable research and development work led at the National Institute of Standard and Technology (NIST) by Dr. Emil Simiu. Accompanying structural analysis platform for linear-elastic structures was also developed, based on modal approach and pre-defined influence coefficients of internal forces in individual members. Thus, by using a large number of simultaneous pressure time-histories from wind tunnel measurements, the dynamic response analysis and structural design are directly performed. The need of using peak combination rules, both for loads and response parameters is thus removed and the wind directionality effect is directly addressed in a transparent analysis procedure (available references are given in [16] to [21].)

A global analysis framework for the computation of wind- induced effects on structures using virtual tools was later proposed and developed by Kwon et al. (2008) [22], Kareem and Kwon (2017) [23]. A sustained effort towards automation is under development in several research groups, including the Structural Dynamics group from the Technical University of Civil Engineering Bucharest (UTCB).

The paper presents a real-time, integrated time-domain framework originally initiated at the National Institute of Standards and Technology (NIST, USA) and independently further developed at UTCB by the author. The computational framework consists of an integrated workflow consisting of linked-in modules- like climatological data, aerodynamic data and signal processing, structural modeling and analysis, design and check. The platform is ready to incorporate the nonlinear response analysis module- under testing phase, in a not too distant future. This will permit rapid extension to post-design phases as damage evaluation, vulnerability and loss estimation analyses, in a complete structural package [7].

Using the wind-induced pressure records (data used with permission) obtained in the wind tunnel on the CAARC (Commonwealth Advisory Aeronautical Council, [24]) of $183 \mathrm{~m}$ tall building, a complete time - and frequency- domain analyses are performed in order to emphasize the distribution of pressure time-histories parameters along the exposed facades, as well as the structural response and its practical implications to design. The adequacy of strength design is then checked through demand-to-capacity ratios (DCR) for members, altogether with deformability and comfort criteria.

\section{Standard-, numerical-, and experimental-based wind loads evaluation}

The wind hazard parameter for design is provided by the Romanian Wind Design Code CR 1-1-4 (2012; [9]), in terms of design base (reference) wind pressure $q_{b}$ at a reference height of $10 \mathrm{~m}$ above the ground, averaged on 10 minutes, corresponding to $2 \%$ probability of yearly exceedance i.e. 50 years MRI. The provisions are fully harmonized with the Eurocode 1 (EC1) format.

Alternatively, experimental approaches as the High Frequency Force Balance (HFFB) technique, wind tunnel (WT) measurements are recommended to estimate more accurately the wind pressure distribution especially for wind-sensitive structures or irregular shaped buildings. Numerical approaches based on Computational Fluid Dynamics (CFD) tool are candidate procedures to replace the cost of experimental tools. 
The more affordable access- from the point-of-view of available equipment and associated cost, to wind pressure measurements, opens the door for the development of a complete time-domain framework, ready to update at a higher level of accuracy the wind loading chain currently used in practice (Figure 1).

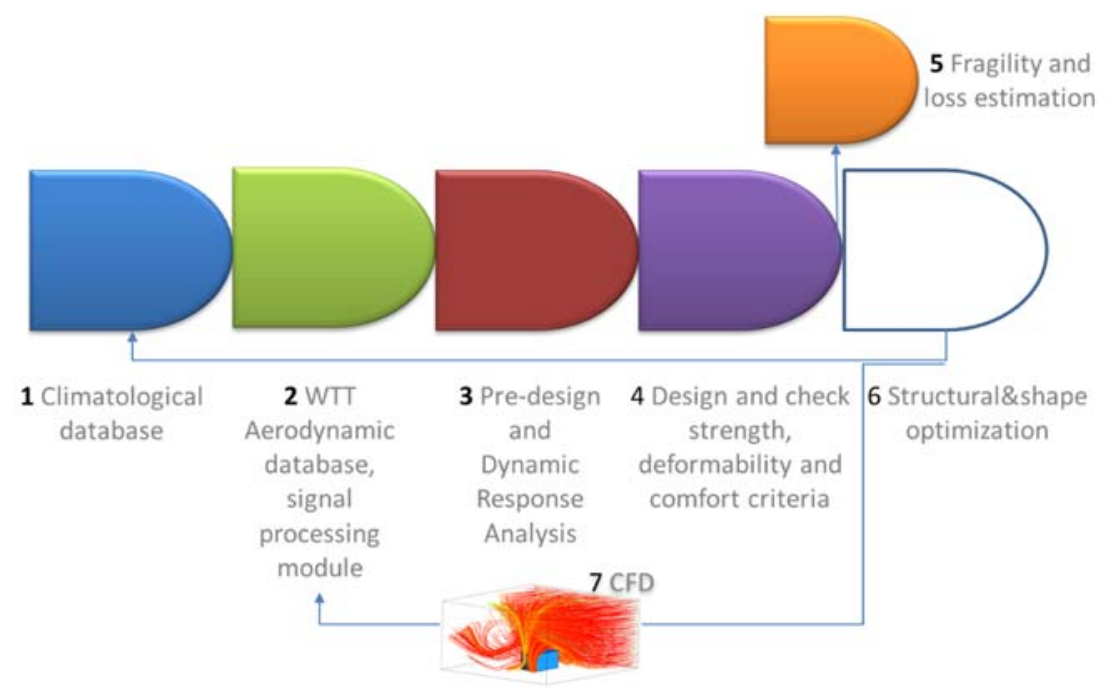

Fig. 2 - Schematic representation of updated wind loading chain for structural design

First, climatological data are provided by large observation databases. This can be augmented for large- unavailable yet MRIs or directional extreme wind speeds data, by performing Monte Carlo simulations [21].

Second, either available aerodynamic databases, or online generators of wind speeds timehistories, can be directly transferred into the structural analysis software and further, to the design and subsequent post-design modules.

The prototype building used in this paper is the CAARC building of 183 height [24], [25]. A schematic view of CAARC building wind tunnel model (data used with permission) is shown in Figure 3. Detailed description on the structural system is given in the next paragraph.

Typical time-histories of the velocity pressure coefficients recorded at the middle upper ports on the façades $\left(\theta=0^{\circ}\right.$ wind blowing direction $)$ are also illustrated.

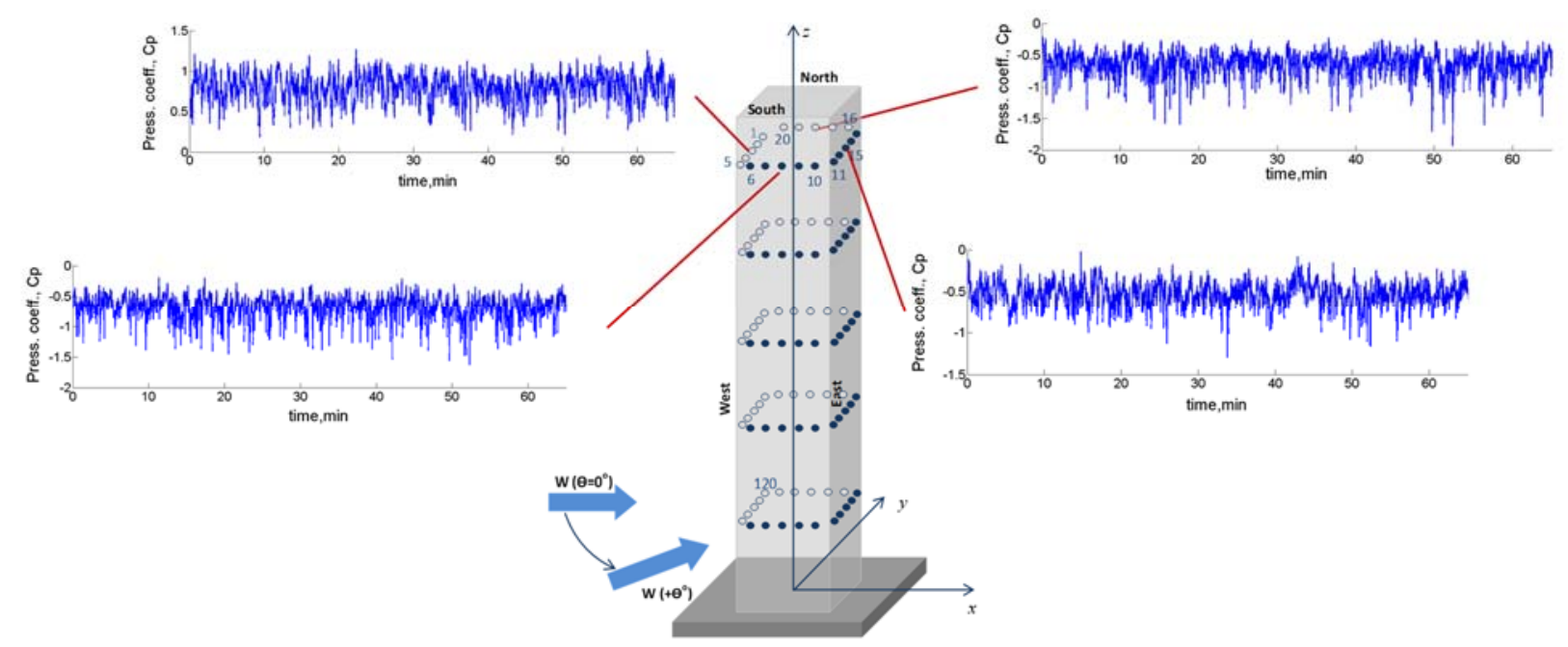

Fig. 3 - Schematic wind tunnel model and typical pressure coefficients time-histories (middle upper ports, $\theta=0^{\circ}$ wind direction) 
The signal processing module of aerodynamic pressure coefficients time-histories, simultaneously recorded at 120 pressure ports, placed on the model's envelope, provides the whole range of information on the input loads parameters to be used by wind and structural engineers.

An example of signal processing analyses output on the recorded pressure coefficients for $0 \mathrm{o}$ wind blowing direction is presented in Figures 4, 5, 6 and 7. The subsequent mean pressure coefficients distribution along the building's model façade for four different wind blowing directions is shown in Figure 4.
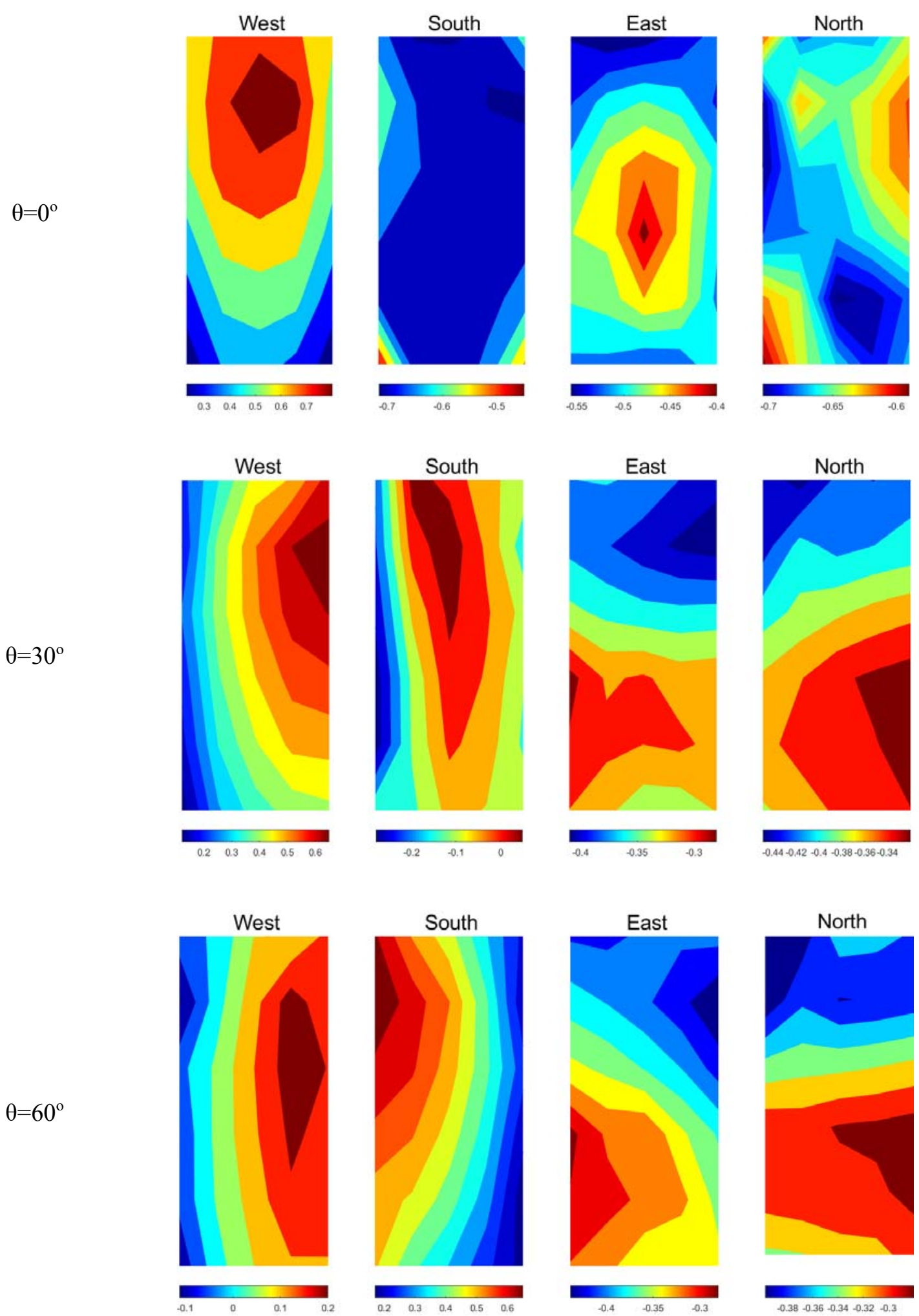


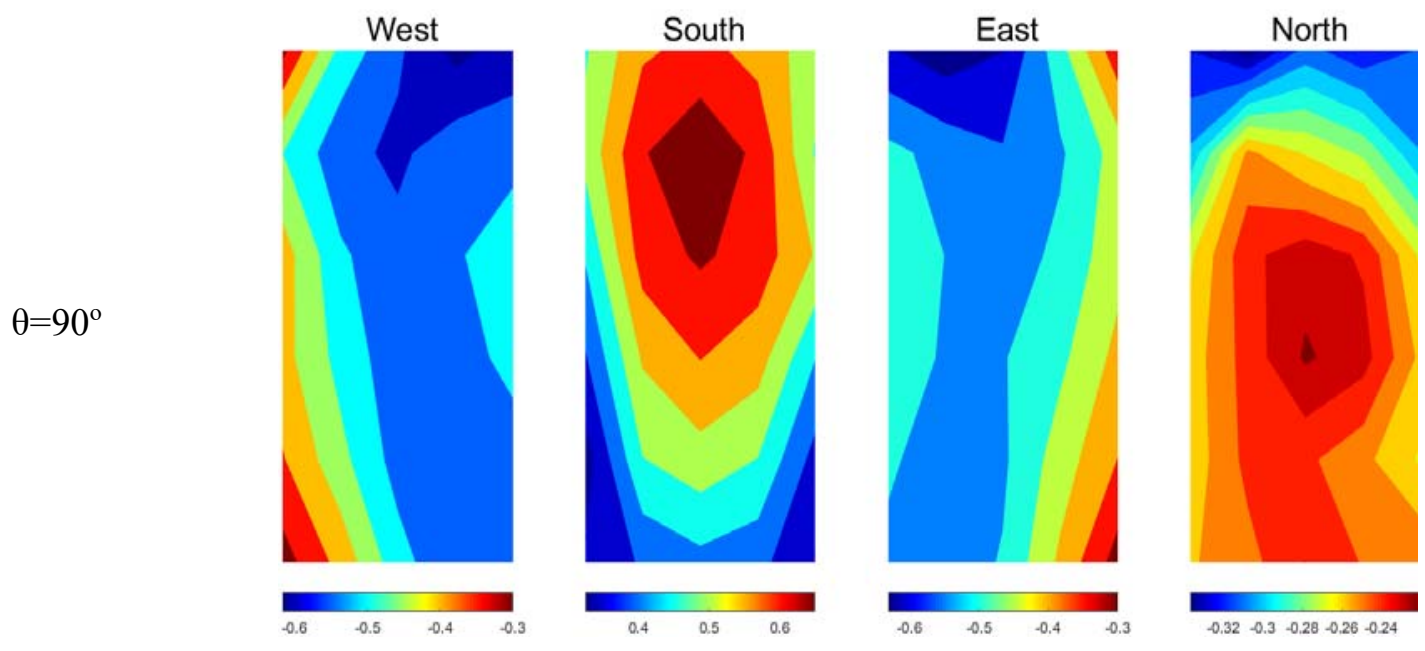

Fig. 4 - Mean pressure coefficients distribution on the model's façade (four wind directions)

\subsection{Signal processing of wind-induced pressure data}

The distribution of wind-induced loads parameters along the prototype's facade can be obtained in real-time, from wind tunnel test procedure by time- and frequency-domain analyses.

Thus, the frequency content indicators (i.e. the frequency bandwidth indicator, the central frequency and the spectral shape indicator) or the total energy of recorded velocity pressure coefficients, are useful parameters to be provided to the structural designers [26], [27].

The frequency bandwidth indicator (Cartwright \& Longuet-Higgins) is given by

$$
\varepsilon=\sqrt{1-\frac{\lambda_{2}^{2}}{\lambda_{0} \lambda_{4}}} \in(0,1)
$$

where, the $i^{\text {th }}$ spectral moment about the mean in the equation (1) is given by

$$
\lambda_{i}=\int_{0}^{\omega_{N}} \omega^{i} S_{x}(\omega) d \omega
$$

$S_{x}(\omega)$ in equation (2) is the Power Spectral Density (PSD) function of signal, and $\omega_{N}$ is the Nyquist circular frequency [26].

In Figure 5, the distribution along the model's envelope of the pressure coefficients frequency bandwidth indicator- $\varepsilon$ is presented for four wind blowing directions. In the along-wind direction, the frequency bandwidth decreases from the center to the edges- in the windward, while in the leeward decreases from the edge to the center. In the across-wind direction however, this decreases through the span length between the edges.
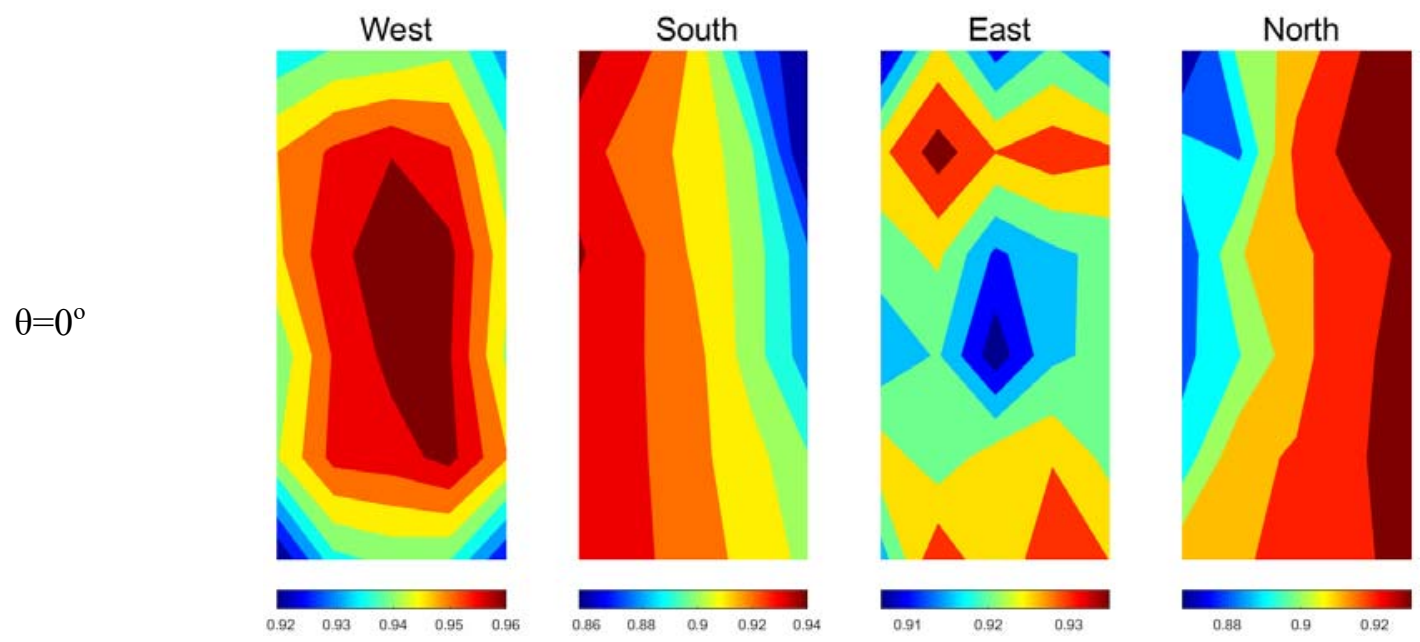

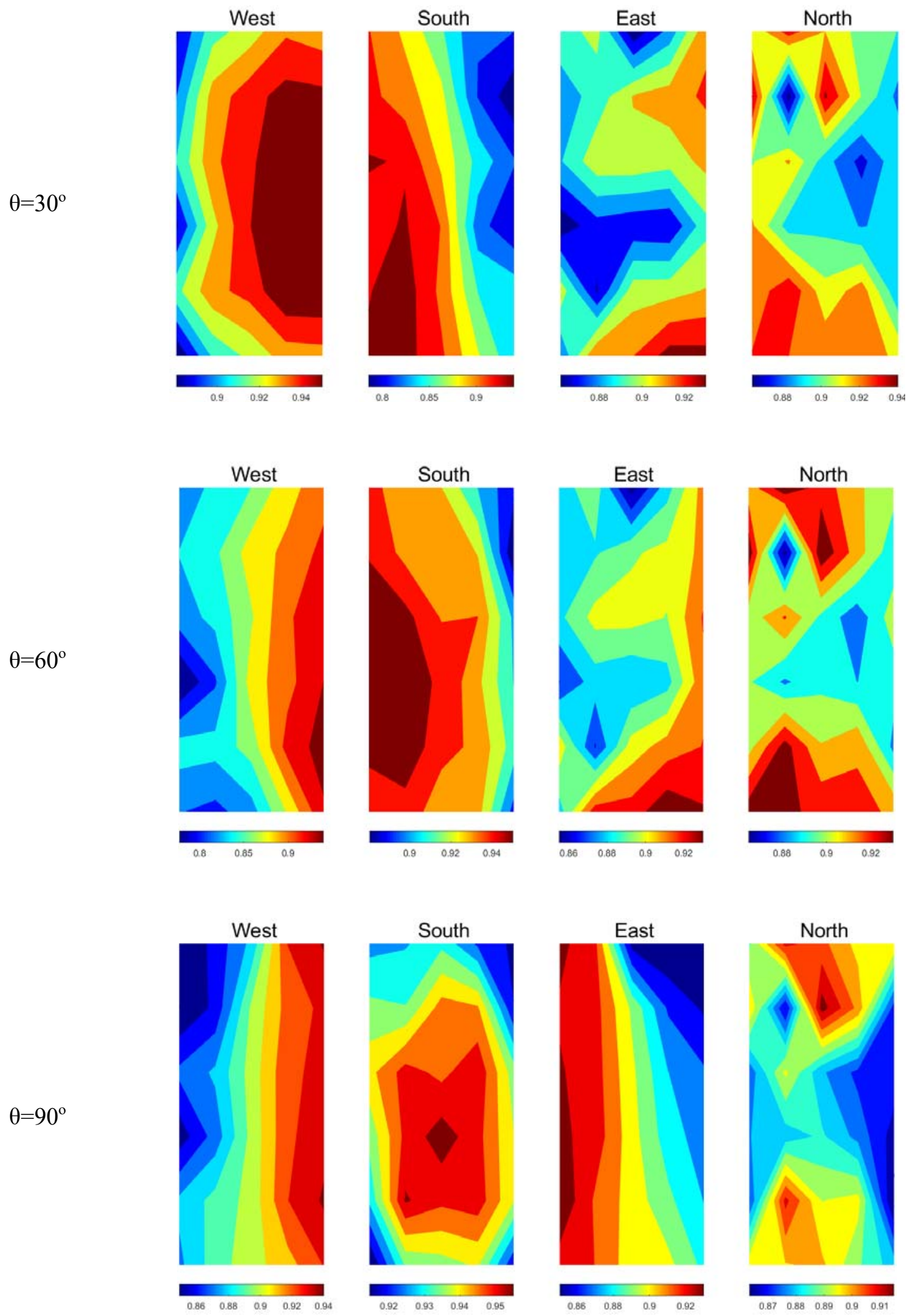

Fig.5 - Frequency bandwidth indicator- $\varepsilon$ of pressure coefficients time-series on the prototype's façade (four wind directions)

In the Figure 6, typical pressure coefficients PSD functions are presented, corresponding to four pressure ports located at the top of the building on the four facades $\left(0^{\circ}\right.$ wind blowing direction only). The records are low-pass filtered in the frequency- domain. The along- and across-wind induced pressure spectral configurations are clearly defined. 

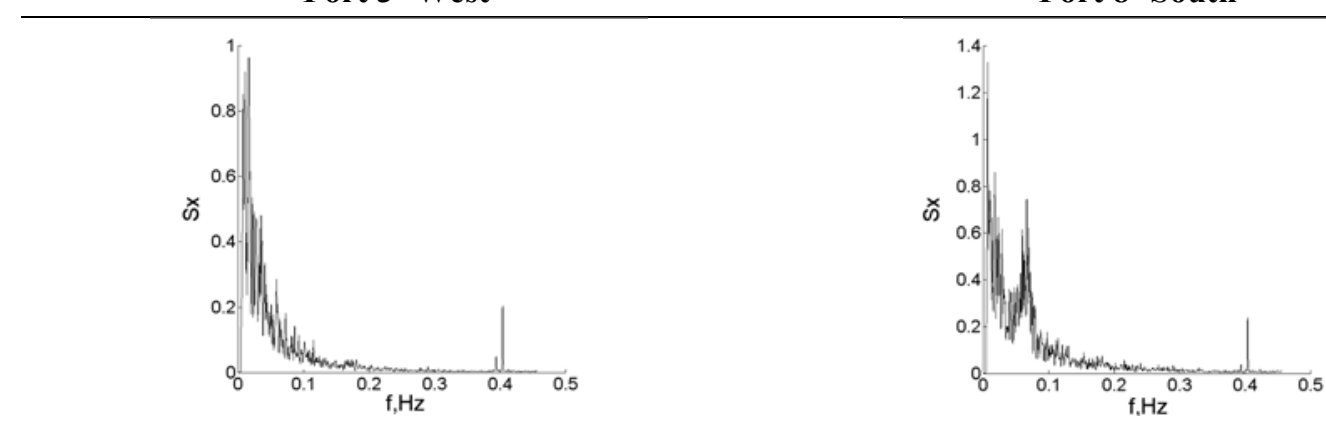

Port 13- East

Port 18- North
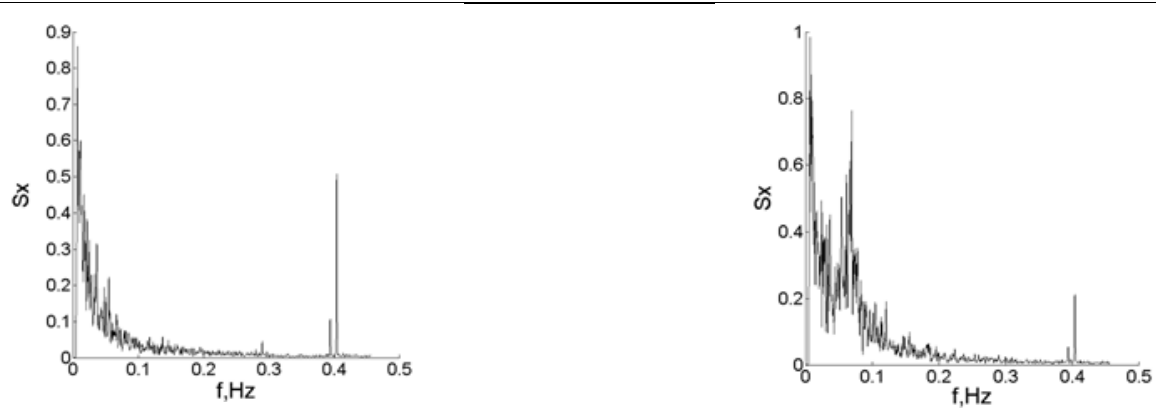

Fig. 6 - PSD functions of pressure coefficients at top middle ports on the model's façade $\left(\theta=0^{\circ}\right.$ wind direction) The maximum (total) energy distribution of velocity pressure coefficients distributions along the model's façade for the same four wind blowing directions is presented in the Figure 7.

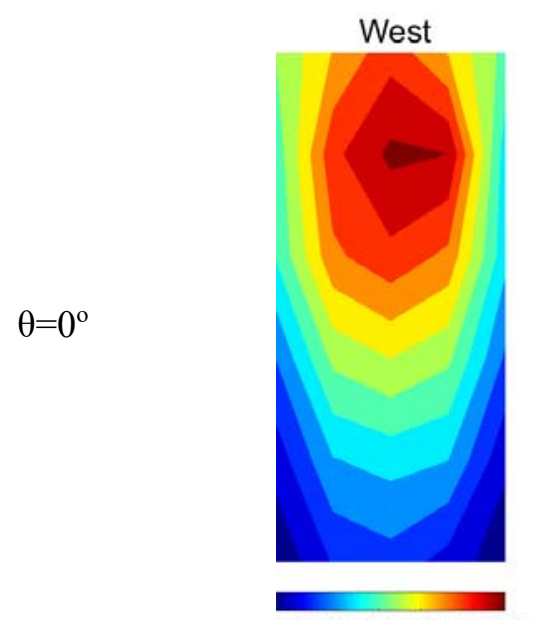

100020003000400050006000

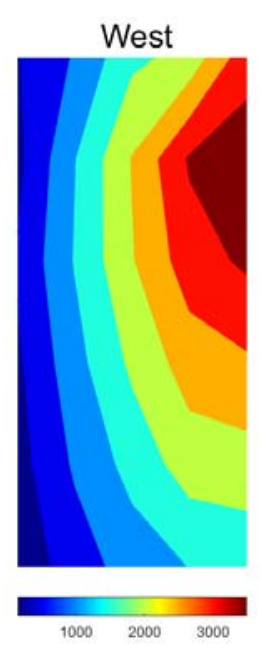

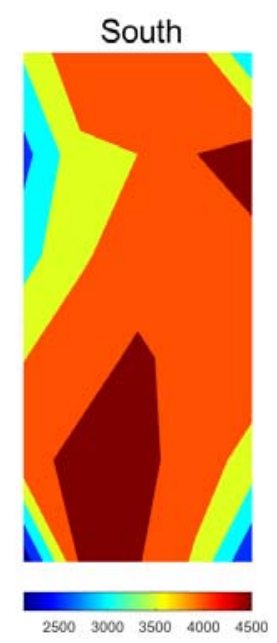
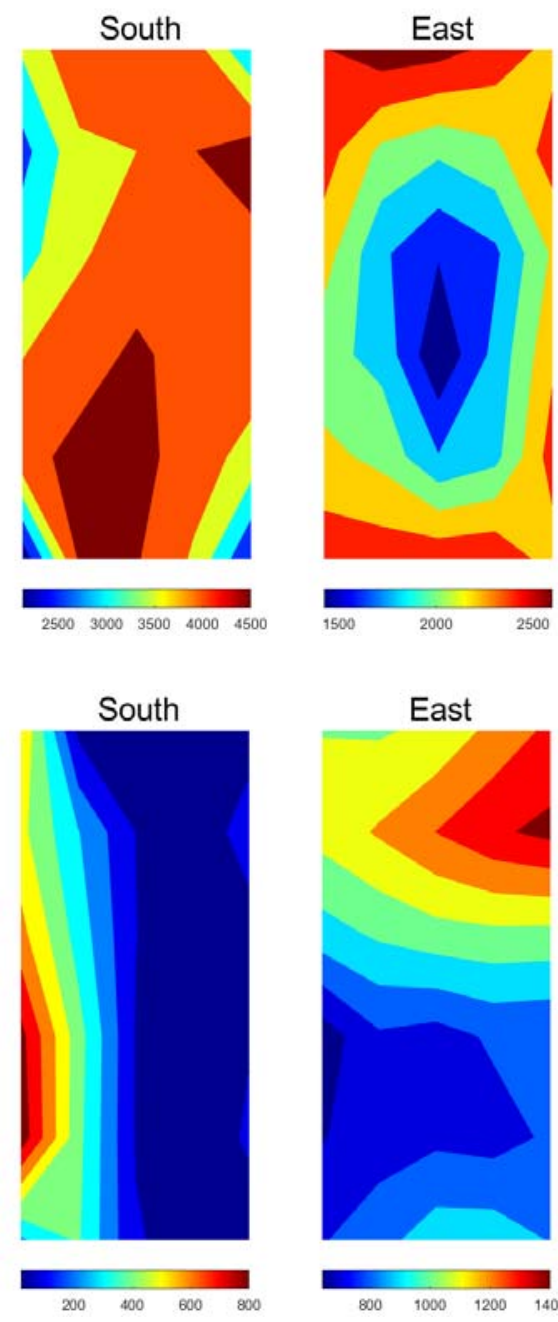
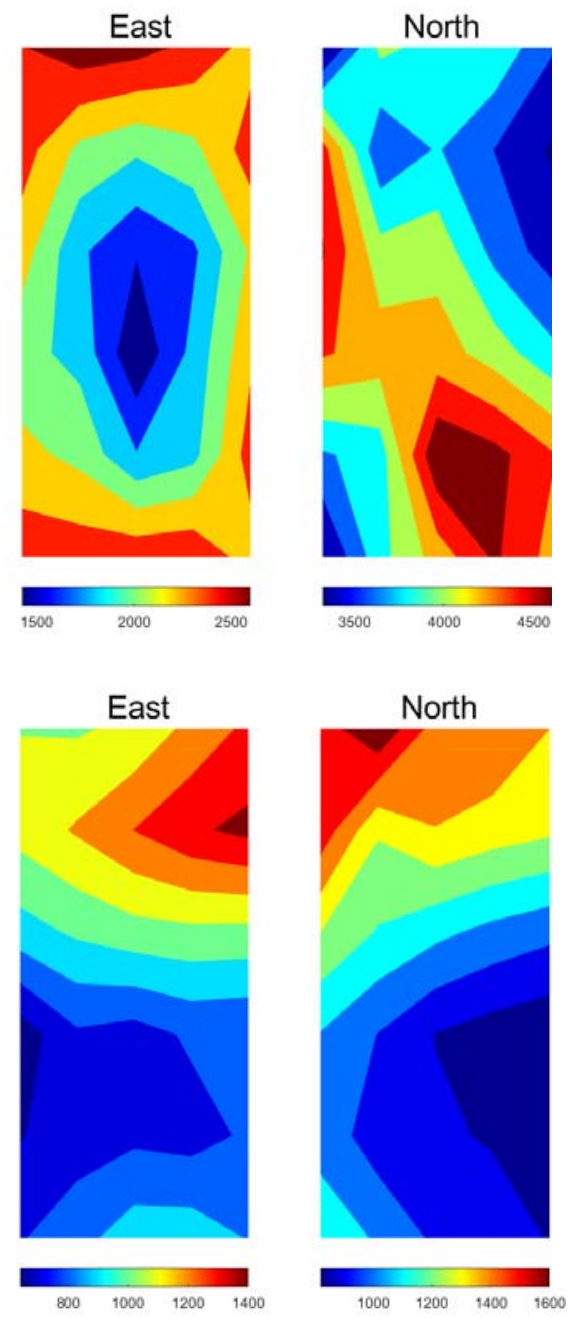

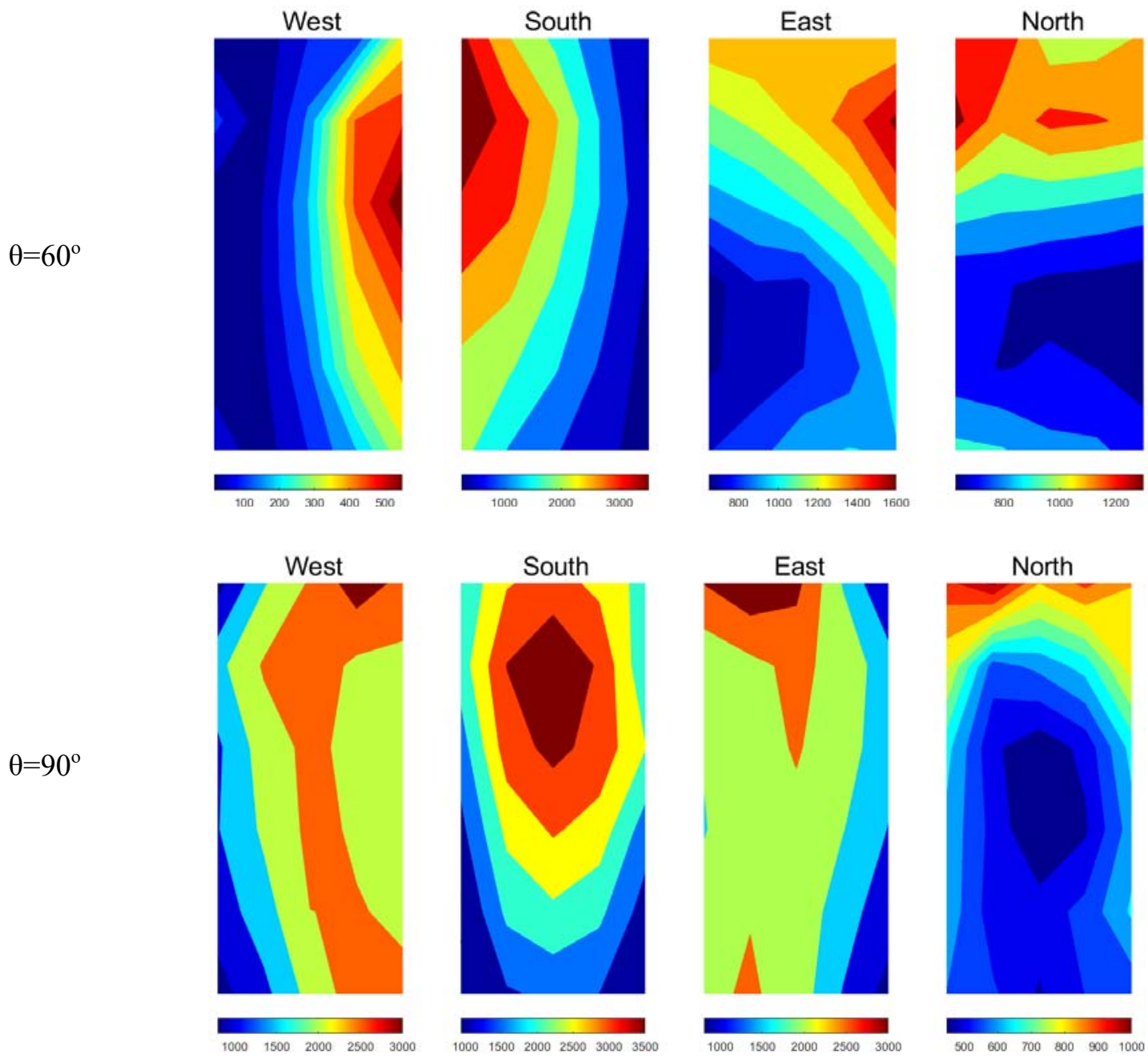

Fig. 7 - Velocity pressure coefficients energy distribution on the prototype's façade (1/Hz; four wind directions)

For $0^{\circ}$ wind blowing direction, the maximum pressure energy distribution is obviously larger on the leeward façade $(\mathrm{N})$ to the top, and on the across incident façade (S) rather uniformly distributed, with larger values at the base. Gradually wind directionality change leads to a decrease of pressure energy when compared to perpendicular flow action due to wind flow detaching at the edges.

\section{Wind-induced structural dynamic response analysis}

The wind-induced dynamic response analysis is performed by a built-in Matlab-based (CMathworks Inc.) integrated package WDyna 3.0 developed by the author (Iancovici, 2019; [28]). This incorporates an efficient State-Space formulation algorithm for the integration of differential equations of motion, that allows further implementation of either nonlinear response analysis solvers (geometric or/and physical) and fluid-structure interaction (FSI) modules, under development phase [7].

Thus, the behavior of a MDOF system subjected by arbitrary loads is described by a $n$-coupled second order non-homogenous differential equations

$$
\boldsymbol{M} \ddot{\boldsymbol{x}}(t)+\boldsymbol{C} \dot{\boldsymbol{x}}(t)+\boldsymbol{F}_{\boldsymbol{r}}(\boldsymbol{x}, \dot{\boldsymbol{x}}, t)=\boldsymbol{F}(t)
$$

where, $\boldsymbol{M}$ and $\boldsymbol{C}$ are the mass and damping matrices. The vector $\boldsymbol{F}_{\boldsymbol{r}}(\boldsymbol{x}, \dot{\boldsymbol{x}}, t)$ consists of restoring forces and may reproduce the effects of linear-elastic or nonlinear behavior (i.e physical or/and geometrical) as well. For linear-elastic systems, the restoring forces vector becomes $\boldsymbol{F}_{\boldsymbol{r}}(\boldsymbol{x}, \dot{\boldsymbol{x}}, t)=\boldsymbol{K} \boldsymbol{x}(t)$, where $\boldsymbol{K}$ is the stiffness matrix of the structure. 
Here, $\ddot{\boldsymbol{x}}(t), \dot{\boldsymbol{x}}(t)$ and $\boldsymbol{x}(t)$ are the response accelerations, velocities and displacements vector, while $\boldsymbol{F}(t)$ represents the aerodynamic loads vector consisting of along-, across- and torqueinduced components.

The State-Space model uses state variables to describe the behavior of a dynamic system through a set of first-order differential equations, rather than the initial second order differential equations [29]. Thus, the number of states is equal to the order of the differential equation. Denote $\boldsymbol{z}$ the state vector of $(2 n, 1)$ dimension $(n$ - is the number of degrees of freedom), consisting of displacement vector $\boldsymbol{x}$ of $(n, 1)$ dimension and the velocity vector $\dot{\boldsymbol{x}}$ of $(n, 1)$ dimension.

Thus,

$$
z_{1}=x
$$

and

$$
\mathrm{z}_{2}=\dot{\boldsymbol{x}}
$$

Therefore, $\dot{\boldsymbol{z}}_{2}=\ddot{\boldsymbol{x}}$ and the original second order differential equations for linear-elastic systems can be rewritten as

$$
\dot{z}=\left[\begin{array}{c}
\dot{z}_{1} \\
\dot{z}_{2}
\end{array}\right]=\left[\begin{array}{c}
\dot{x} \\
\ddot{x}
\end{array}\right]=\left[\begin{array}{cc}
0 & I \\
-M^{-1} K & -M^{-1} C
\end{array}\right]\left[\begin{array}{l}
Z_{1} \\
z_{2}
\end{array}\right]+\left[\begin{array}{c}
0 \\
M^{-1}
\end{array}\right] F
$$

Equation (6) can be expressed in the matrix form as follows

$$
\dot{\mathbf{z}}=A z+B F
$$

The vector of displacements yields then from equation (4) as

$$
y=z_{1}=C z+D F
$$

where, $\dot{\boldsymbol{z}}$ is the vector of first order state- variables, $\boldsymbol{z}$ is the state variable vector and $\boldsymbol{y}$ is the output vector.

In the state-space formulation, $\boldsymbol{A}$ is called the state matrix, $\boldsymbol{B}$ is the input matrix, $\boldsymbol{C}$ is the output matrix, while $\boldsymbol{D}$ is the transfer (transmission) matrix given [29]

$$
\begin{aligned}
\boldsymbol{A} & =\left[\begin{array}{cc}
\mathbf{0}_{n} & \boldsymbol{I}_{\boldsymbol{n}} \\
-\boldsymbol{M}^{-1} \boldsymbol{K} & -\boldsymbol{M}^{-1} \boldsymbol{C}
\end{array}\right] \\
\boldsymbol{B} & =\left[\begin{array}{c}
\mathbf{0}_{\boldsymbol{n}} \\
\boldsymbol{M}^{-1}
\end{array}\right] \\
\boldsymbol{C} & =\left[\boldsymbol{I}_{2 n, 2 n}\right] \\
\boldsymbol{D} & =\left[\mathbf{0}_{2 n, n}\right]
\end{aligned}
$$

By solving the equations (7) and (8), the velocity vector $\dot{\boldsymbol{x}}$, acceleration vector $\ddot{\boldsymbol{x}}$ and displacement vector $\boldsymbol{x}$, will be efficiently calculated using two first order differential systems of equations instead of the original second order differential system of equations. This brings significantly higher numerical efficiency when dealing with both, large dimension linear or nonlinear behavior structural systems, and long duration loads. Further, any other response parameter (strains, stresses, internal forces, energies) becomes available for design and postdesign purpose.

\subsection{Case study}

The prototype structure of the CAARC model is a regular 60 story RC shear frame building, modeled with $3 \mathrm{DOF} /$ floor, i.e. sways in $x$ - and $y$-directions and torque around $z$-direction (Figure 8). The Young's modulus is considered as $3 \times 10^{7} \mathrm{kN} / \mathrm{m}^{2}$, the columns are of square section $90 \times 90$ (cm) and the slab is $25 \mathrm{~cm}$ thick. 
The damping model chosen is the Rayleigh proportional model, with 3\% damping ratio associated to the Safety Limit State, for the first two lateral sway vibration modes.

The modal information for the first nine vibration modes is given in Table $1 ; P_{x}, P_{y}$ and $P_{z}$ are the mass mode participation factors, corresponding to lateral sway $x$ - and $y$-, and torque around vertical $z$-axis, respectively.

The design reference mean hourly wind speed for the prototype structure is chosen as $27 \mathrm{~m} / \mathrm{s}$, and the wind speed profile is provided by the Romanian Wind Design Code (Zone III conditions, compatible with WT testing conditions). This is used for the conversion from model to prototype, based on the reduced frequency criterion [16], [21].
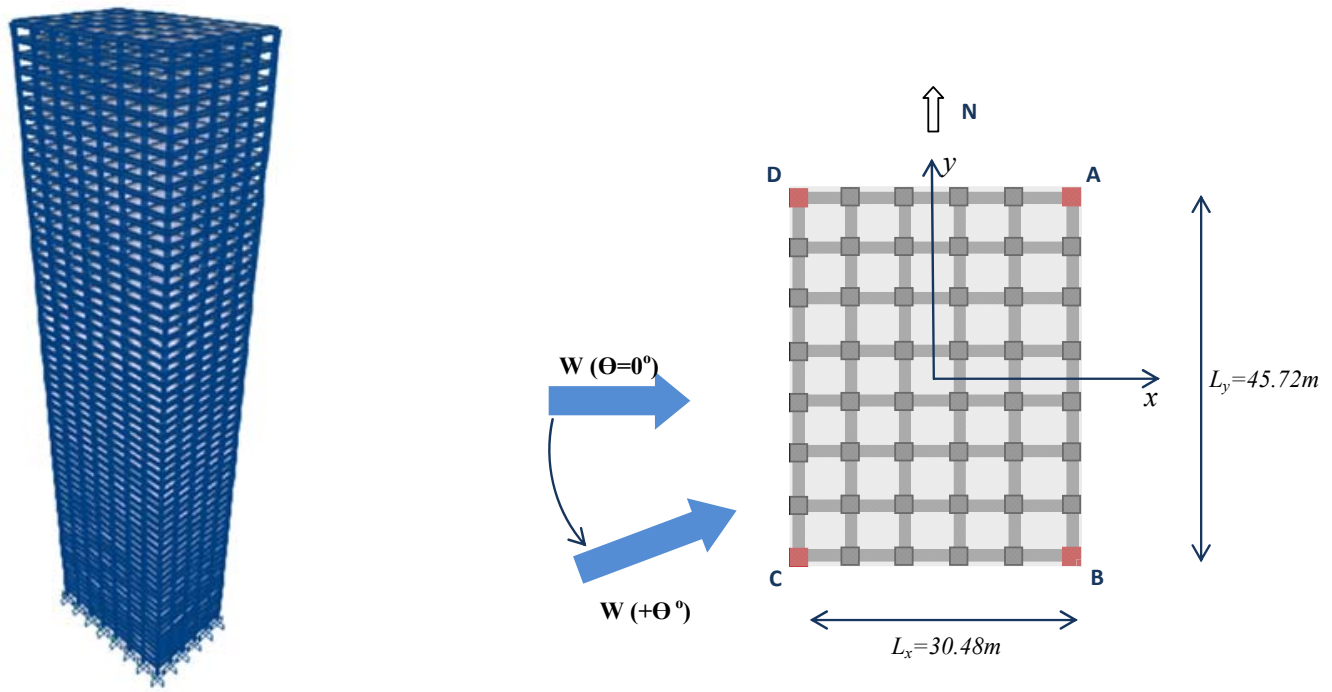

Fig. 8 - Structural system and plan views

Table 1

Structural modal information

\begin{tabular}{cccrrr}
\hline Mode index & $\mathbf{T}, \mathbf{s}$ & Damping ratio, $\mathbf{\%}$ & $\mathbf{P}_{\mathbf{x}}, \mathbf{\%}$ & $\mathbf{P}_{\mathbf{y}}, \mathbf{\%}$ & $\mathbf{P}_{\mathbf{z}}, \mathbf{\%}$ \\
\hline 1 & 3.08 & 3.00 & 0.59 & 80.66 & 0.00 \\
2 & 3.08 & 3.00 & 80.66 & 0.59 & 0.00 \\
3 & 2.68 & 3.03 & 0.00 & 0.00 & 81.25 \\
4 & 1.04 & 4.96 & 6.38 & 2.91 & 0.00 \\
5 & 1.04 & 4.96 & 2.91 & 6.38 & 0.00 \\
6 & 0.90 & 5.56 & 0.00 & 0.00 & 9.28 \\
7 & 0.62 & 7.72 & 0.15 & 3.19 & 0.00 \\
8 & 0.62 & 7.72 & 3.19 & 0.15 & 0.00 \\
9 & 0.54 & 8.79 & 0.00 & 0.00 & 3.34 \\
\hline
\end{tabular}

The time-instant wind-induced pressure $p_{s}$ at a given port $s$ - located at the elevation $z$ above the ground level (Figure 3), is

$$
p_{s}(z, t)=\frac{1}{2} \rho C_{p s}(z, t){\overline{V_{h}}}^{2}(H)
$$

where, $\rho=1.23 \mathrm{~kg} / \mathrm{m}^{3}$ is the air density, $C_{p s}(z, t)$ is the corresponding pressure coefficient at port- $s$ and $\overline{V_{h}}(H)$ is the mean hourly wind speed at the top of the building $(\mathrm{H})$ - according to the mean wind speed profile given in the Romanian Wind Design Code [9].

The corresponding aerodynamic wind force at pressure-port location $s$ is then

$$
F_{s}(t)=p_{s}(t) A_{s}
$$

where, $A_{s}$ denotes the corresponding tributary area of the pressure port- $s$. 
The aerodynamic forces at individual ports aggregates the load vector in equation (3).

Typical time-histories of sway- and torque-induced bending moments in say- the base corner column A (Figure 8), corresponding to $0^{\circ}$ wind blowing direction, are shown in Figure 9.
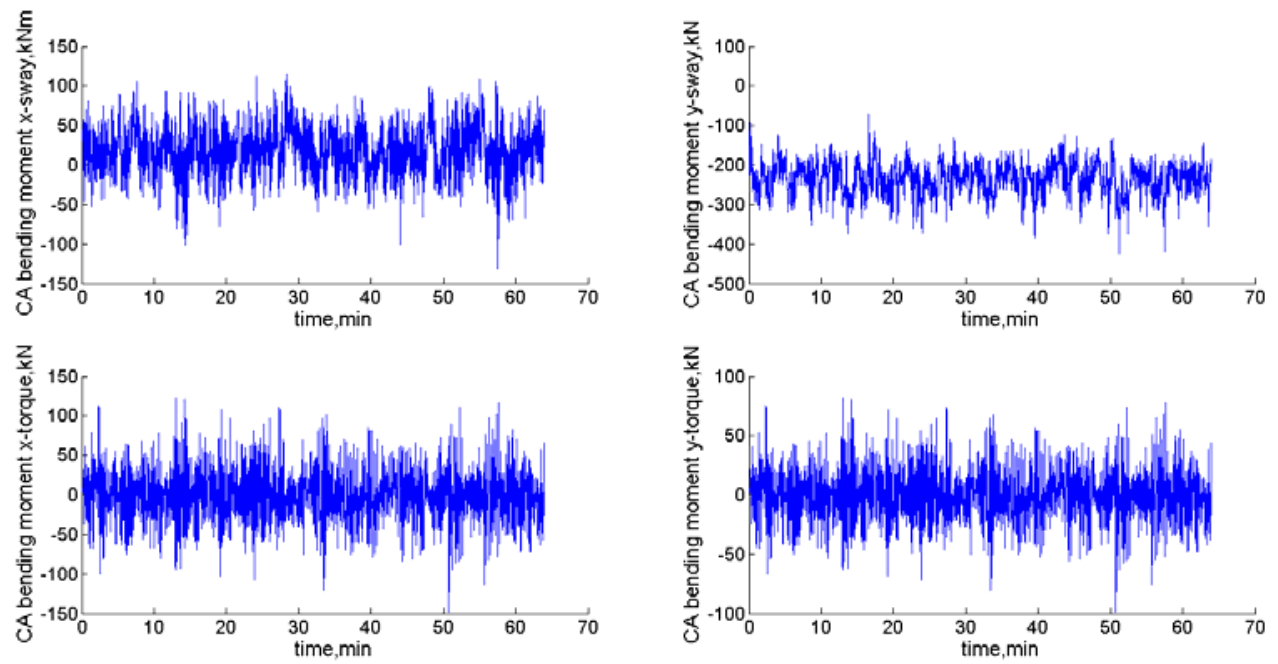

Fig. 9 - Sway-and torque-induced bending moments time-histories in the base column A $\left(\theta=0^{\circ}\right.$ wind direction $)$

The time-histories of internal forces, i.e. the axial force and the bi-axial bending moments, in the same section are illustrated in Figure 10 for the same $\theta=0^{\circ}$ wind direction. The decoupled analysis, in sway- and torque-induced effects, illustrated in Figure 9, is useful for the mitigation of excessive torsional response by e.g. shape and structural optimization modules. The response quantities are straightforward used for strength design and check the compliance with comfort (floor acceleration) and deformability (inter-story drift ratio) limitations.

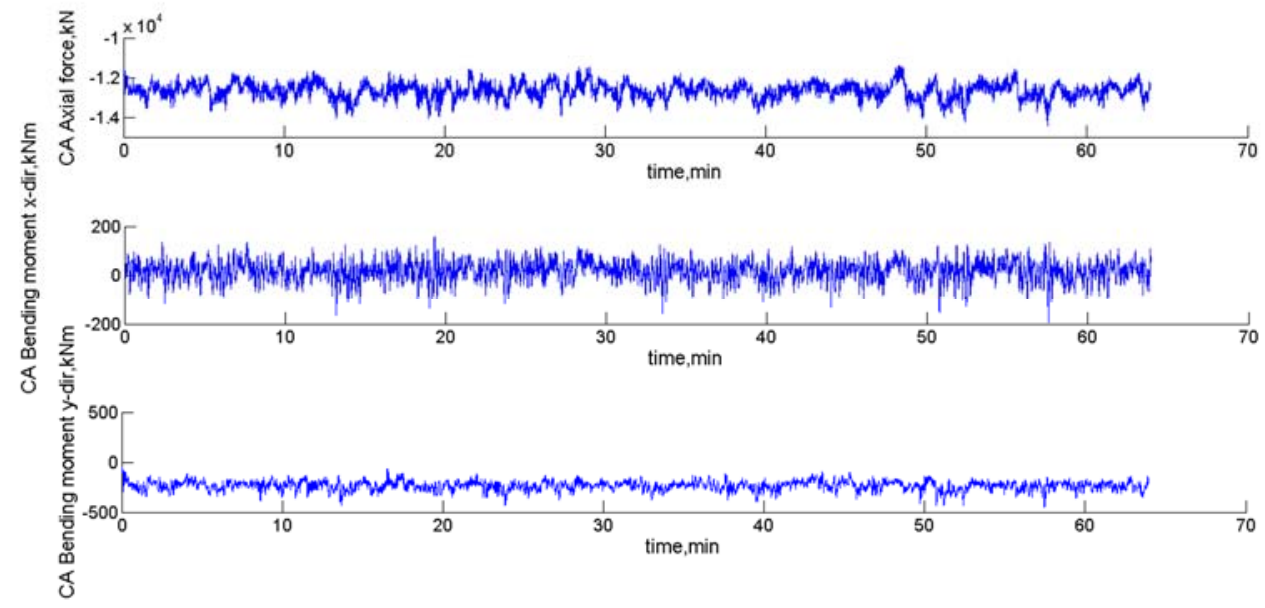

Fig. 10 - Time-histories of internal forces in the base column A $\left(\theta=0^{\circ}\right.$ wind direction $)$

\section{Structural design issues and wind directionality effect}

The adequacy of strength design can be iteratively checked and corrected using either a built-in module or imported interaction surfaces (e.g. by using the XTRACT software) for structural members (e.g. point-in-time triplet $P-M_{x}-M_{y}$ for columns, $M_{x}$ for beams).

In Figure 11 and Figure 12, the demand orbit particle and the capacity surface are represented altogether for two wind directions $\left(\theta=0^{\circ}\right.$ and $\left.\theta=30^{\circ}\right)$, for the corner base columns (Figure 8) at the preliminary design phase. 
Column A

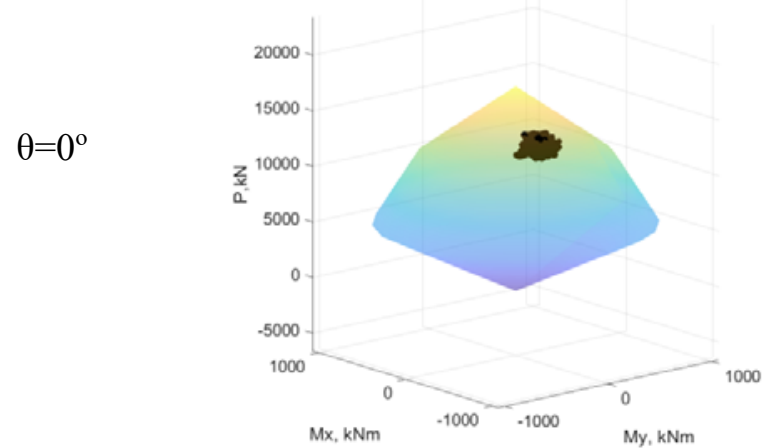

Column C

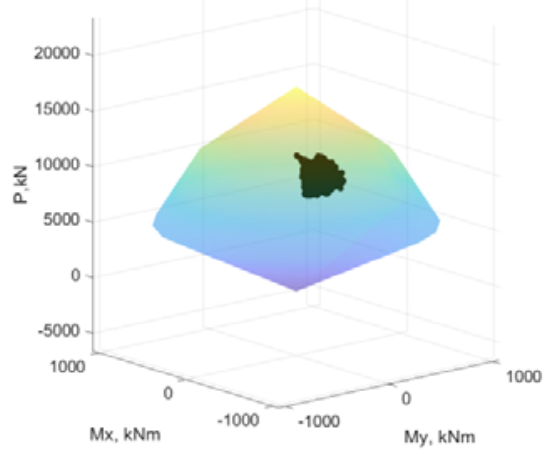

Column B

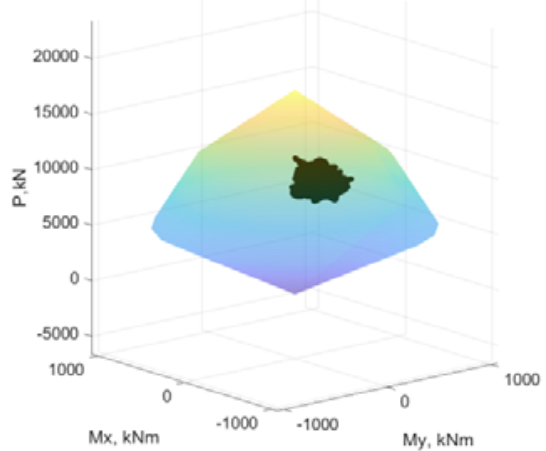

Column D

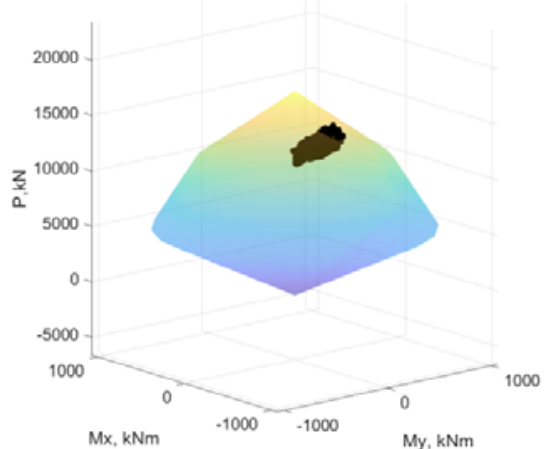

Fig. 11 - Corner base columns point-in-time demand internal forces vs. capacity $\left(\theta=0^{\circ}\right.$ wind direction $)$

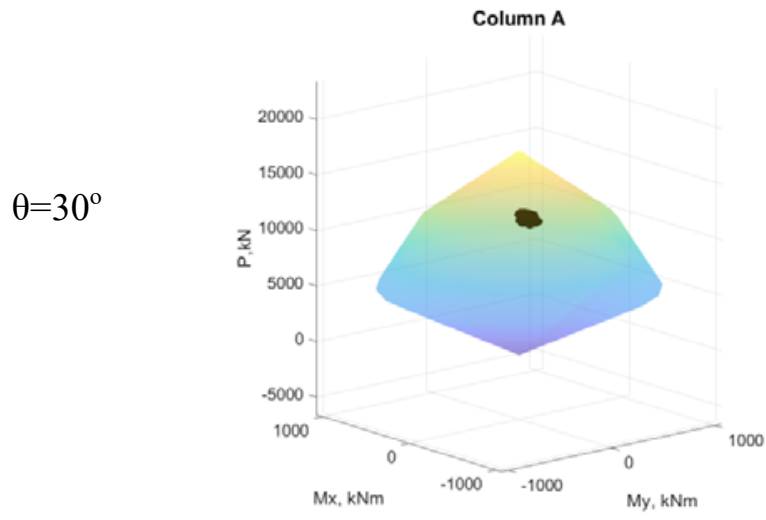

Column C

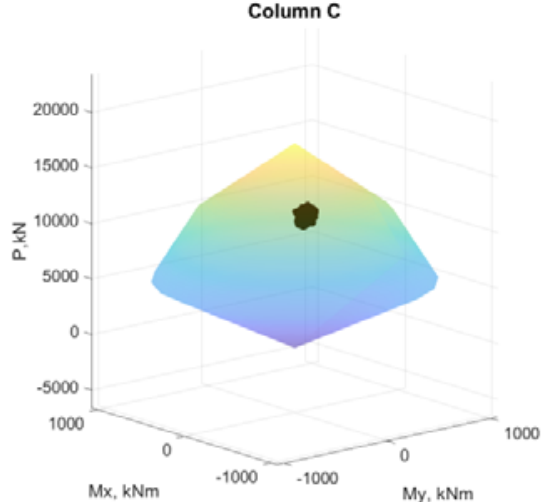

Column B

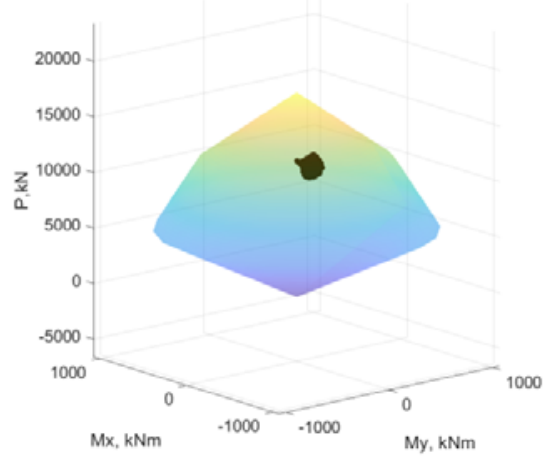

Column D

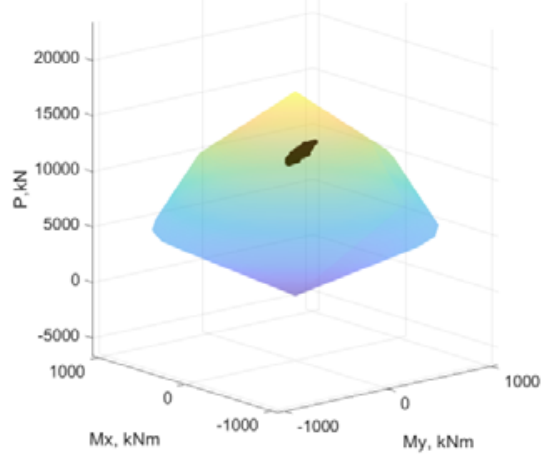

Fig. 12 - Corner base columns point-in-time demand internal forces vs. capacity $\left(\theta=30^{\circ}\right.$ wind direction $)$ 
The Demand-to-Capacity Ratio (DCR) parameter is computed as the ratio of distance from the origin to demand point and in-line from the origin to capacity surface point.

For $\theta=0^{\circ}$ wind direction, the safety criterion is not satisfied for the columns A and D, while the $\theta=30^{\circ}$ wind direction provides demand values in the safety limit for all corner columns. For the structural design however, the effect of wind directionality is to be considered.

By virtue of symmetry, a wind rosette of $\Delta \theta=+10^{\circ}$ wind directionality increment (from $0^{\circ}$ to $90^{\circ}$ ) is only considered in the analyses (Figure 13).
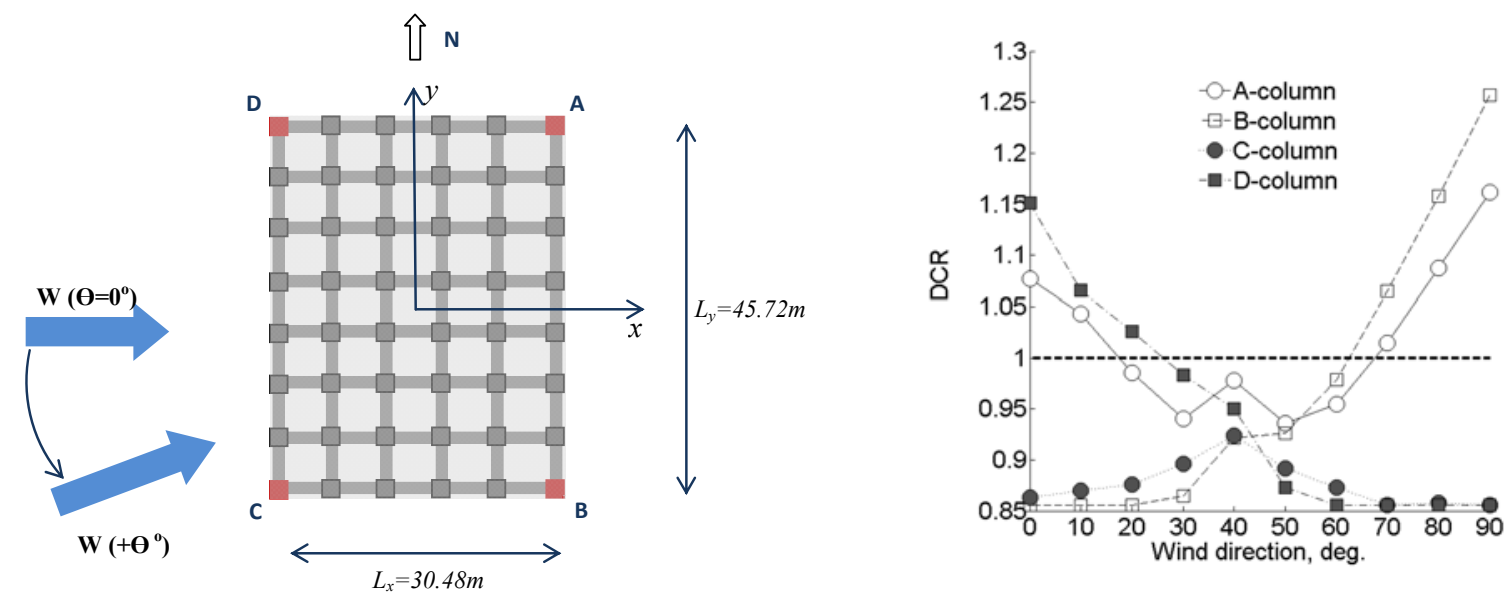

Fig. 13 - Wind directionality effect on the demand-to-capacity ratios (DCR) for the base corner columns

For all the wind blowing directions, the column $C$ satisfies the safety criteria, while the other columns are out of safety criteria at different wind blowing directions. For the complete wind directionality rosette however, all the base columns are out of safety criterion. So, the next step to redesign and check the structural members, is necessary. Available climatological database, i.e. wind speed rosette for a given site, for different MRIs, will augment this analysis section.

Deformability criteria is controlled through inter-story drift ratios associated to different limits states (Serviceability-S, Life Safety-LS and Immediate Occupancy-IO), as provided by design codes or other standards like e.g. FEMA 356 [30]. The criterion can be checked directly from the time-history analysis results as shown here for six stories, for $\theta=0^{\circ}$ wind direction only (Figure 14).
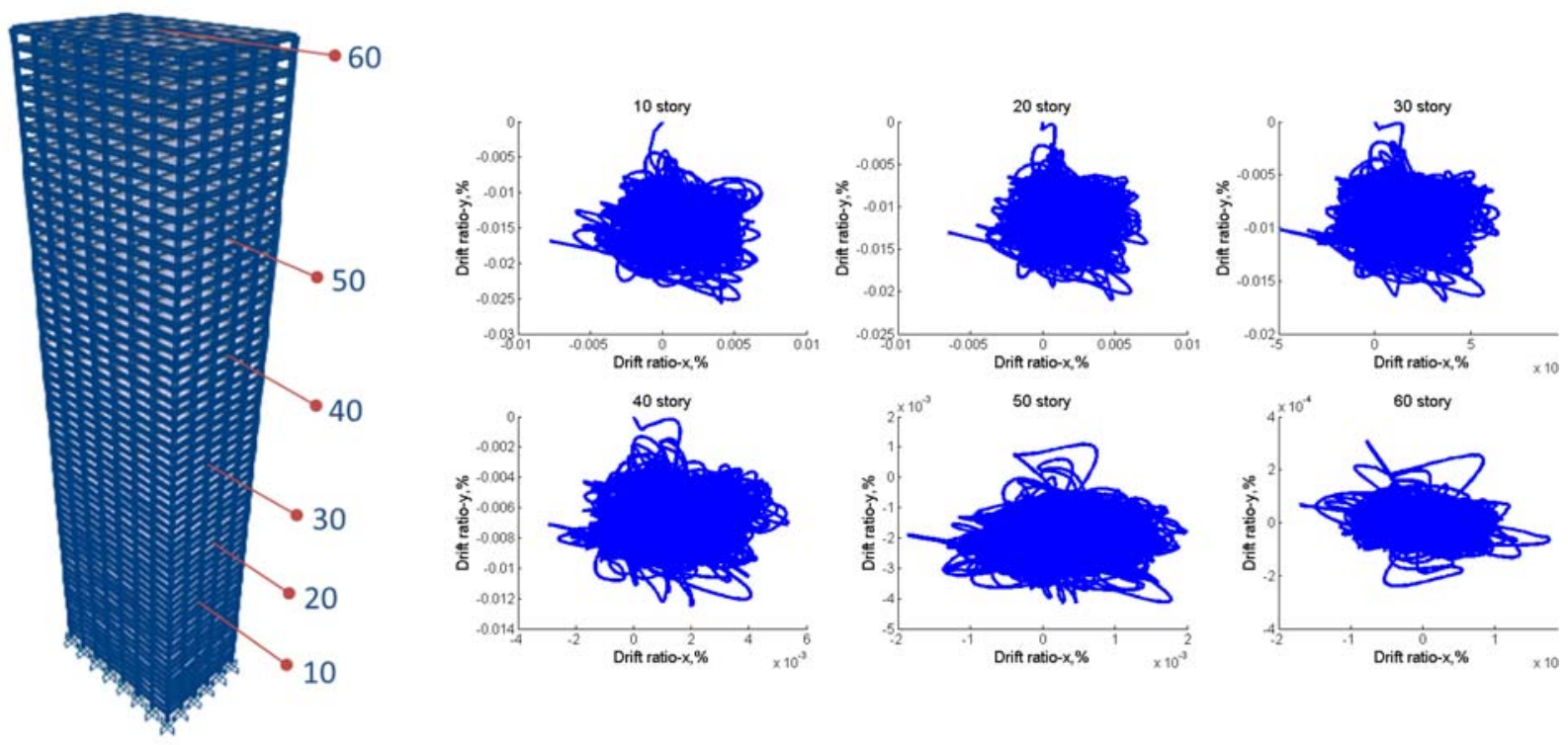

Fig. 14 - Orbit particles of inter-story drift ratio along the building height ( $\theta=0^{\circ}$ wind direction) 
Comfort criteria specifications are also to be straightforward checked from the time-histories of floor acceleration responses. In Figure 15, the orbit particles of accelerations at various floor levels are compared with design specifications [9].
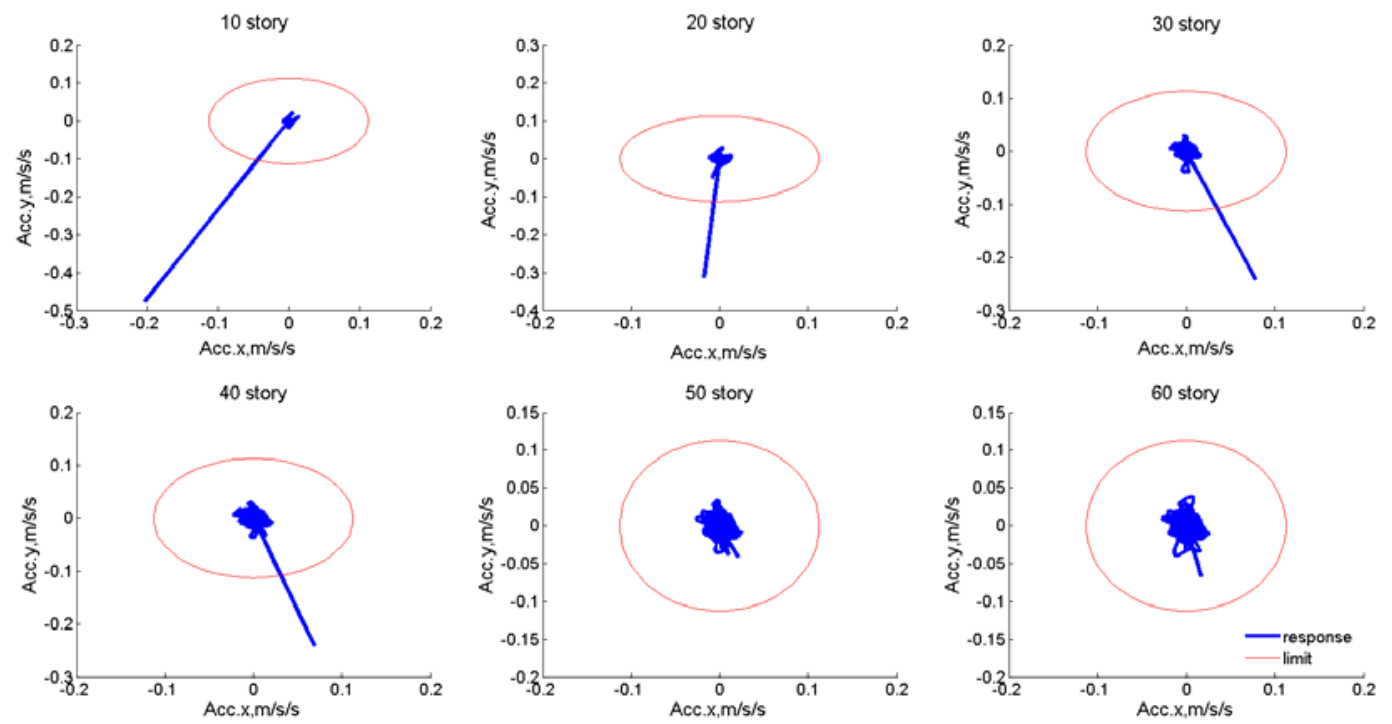

Fig. 15 - Floor acceleration orbit particles and comfort limit along the building height ( $\theta=0^{\circ}$ wind direction)

For Serviceability/Habitability Limit State, the reference mean wind speed is taken as 0.75 from the Safety Limit State associated reference mean wind speed (MRI=10 yr.; [9]).

The story RMS accelerations distributions on the building height, for all wind blowing directions, are summarized in Figure 16.

The influence of wind directionality on the across-wind response are clearly identified as well as the torque floor acceleration, prerequisite for the building shape optimization module.
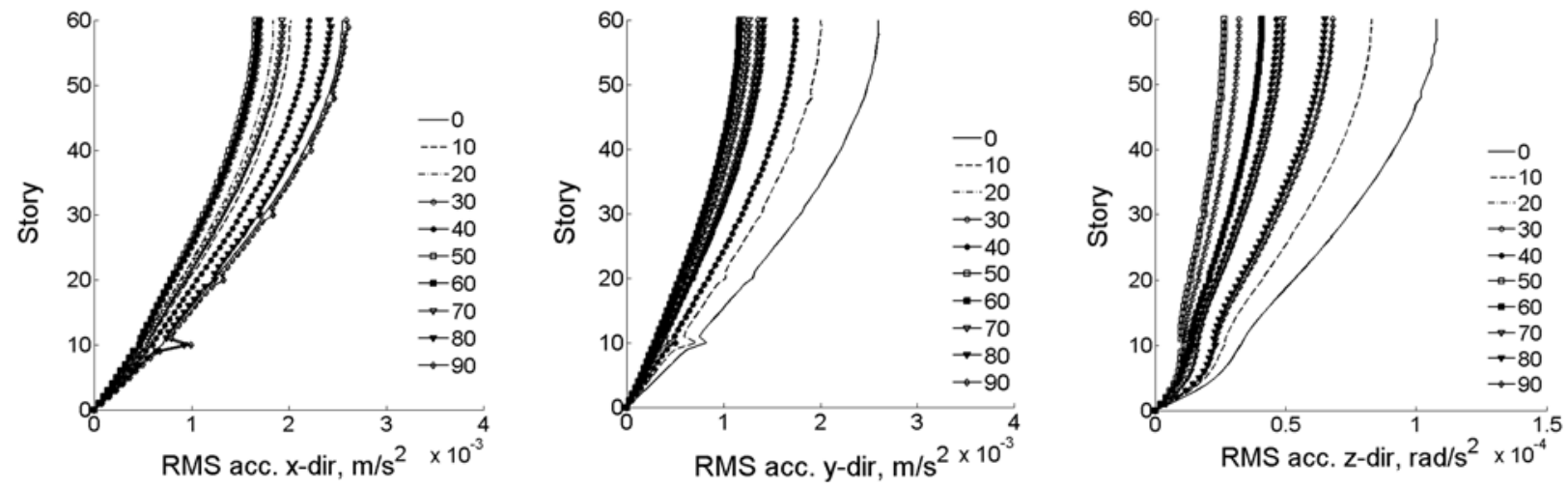

Fig. 16 - Story RMS accelerations in the $x$-, $y$ - and $z$ (torque)-directions ( $\left(\theta=0^{\circ}\right.$ to $90^{\circ}$ wind directions)

For both, safety and comfort limit states however, the peaks-over-threshold approach can be implemented in a probabilistic analysis framework [26], [27].

\subsection{Nonlinear dynamic response analysis for wind loads}

A complete workflow however, must incorporate the nonlinear dynamic response analysis (NDA) tool, in order to reproduce more accurately the structural behavior. This will allow the implementation of higher levels analysis modules as vulnerability analysis, damage state estimation as well as risk and loss estimation. 
Current developments in progress using a numerically efficient nonlinear solver (Iancovici et al., 2019 [28]) showed very encouraging results for typical structures [7]. Large loading durations are possible to be handled in an effective manner, in order to produce at highest capabilities' accurate information for the design stage as well as for the post-design stage.

\section{Conclusions}

The time-domain approach for the analysis, practical design and post-design stages of building structures for wind loads, opens the door for higher accuracy integrated packages, including experimental and associated signal processing tools, structural analysis and design platforms, optimization, vulnerability and risk analysis packages. For tall buildings however, this becomes more important than for regular buildings, in order to overcome the inherent code and analysis methods limitations.

The paper presents an integrated platform for the analysis and design of tall buildings to wind loads, directly from the time-histories of pressure data recorded in the wind tunnel. The climatological data and the aerodynamic data are directly incorporated in a comprehensive analysis module. The efficient numerical integration based on the State-Space approach is able to handle a large number of records and long duration loads. Thus, the time-histories of structural response parameters are used without any intervention on various assumptions- like modal and directional combination, to straightforward design and check the adequacy with the comfort, deformability and safety criteria.

The implementation of an efficient Nonlinear Dynamic Analysis (NDA) module, based on recent developments [7], will bring significant steps forward for structural engineering applications.

After careful validation, the Computational Fluid Dynamics (CFD) tool is a valid candidate to replace WT measurements and play a major role in the integrated package that would produce in a not too distant future, safer and more cost-effective structures.

\section{Acknowledgements}

The author highly acknowledges the support of Dr. Emil Simiu and the DAD-HR research team from the National Institute of Standards and Technology (NIST), USA.

\section{References}

[1] Lungu, D., Vacareanu, R., Aldea, A., Arion, C. (2000). Advanced Structural Analysis. Conspress Ed., Bucharest

[2] Council on Tall Buildings and Urban Habitat (2008). Recommendations for the Seismic Design of High-Rise Buildings. Ed. Antony Wood, Publisher: CTBUH, Chicago, ISBN: 978-0-939493-26-5

[3] Pacific Earthquake Engineering Research Center (2010). Guidelines for Performance-Based Seismic Design of Tall Buildings. Report no.2010/05-TBI

[4] Pacific Earthquake Engineering Research Center (2017), Guidelines for Performance-Based Seismic Design of Tall Buildings,. Version 2.03. Report no.2017/06-TBI

[5] ASCE (2010) Minimum Design Loads for Buildings and Other Structures, ASCE/SEI 7-10. American Society of Civil Engineers, Reston, Virginia.

[6] Iancovici, M., Vezeanu, G. (2016). A time-domain approach for the Performance-based Design Analysis of tall buildings in Bucharest. The 1940 Earthquake. Issues, Insights and Lessons Learnt, R. Vacareanu and C. Ionescu (eds.), Proceedings of the Symposium Commemorating 75 Years from November 10, 1940 Vrancea Earthquake, Springer Natural Hazards Series, Springer International Publishing, Part III, pp 333-350, DOI 10.1007/978-3-319-29844-3_23, ISBN 978-3-319-29843-6

[7] Iancovici M., Nica G., Vacareanu R., Pavel F. (2019) Time domain wind-induced structural damage evaluation. Proceedings of the $2^{\text {nd }}$ National Conference on Wind Engineering (2NCWE2019), 6-7 June 2019, Bucharest

[8] ASCE (2019). Prestandard for Performance-based Wind Design. American Society of Civil Engineers, Reston, Virginia

[9] CR-1-1-4 (2012). Code for the evaluation of wind loads on structures. Ministry of Regional Development and Tourism, Romania (in Romanian) 
[10] Kwon, D., Kareem, A. (2013). Comparative study of major international wind codes and standards for wind effects on tall buildings. Engineering Structures, 51 (2013), 23-35

[11]Zhou, Y., Kijewski, T., Kareem, A. (2003). Aerodynamic Loads on Tall Buildings: An Interactive Database. Journal of Structural Engineering, ASCE, 129(3), 394-404

[12] Kijewski, T., Kareem, A. (1998). Dynamic wind effects: a comparative study of provisions in codes and standards with wind tunnel data. Wind and Structures, 1(1), 77-109

[13] National Institute of Standards and Technology (2005). Federal Building and Fire Safety Investigation of the World Trade Center Disaster: Final Report on the Collapse of the World Trade Center Towers. NIST NCSTAR 1. Gaithersburg, MD.

[14] Irwin, P., Denoon, S., Scott, D. (2013). Wind Tunnel Testing of High-Rise Buildings. Publisher CTBUH\& IIT and Routledge / Taylor and Francis Group, Chicago, ISBN: 978-0-415714-59-4

[15] Whalen, T.M., Shah, V., Jang, J.-S. (2000). A Pilot Project for Computer-Based Design of Low-Rise Buildings for Wind Loads - The WiLDE-LRS Users's Manual, NIST GCR-00-802, National Institute of Standards and Technology (NIST), Gaithersburg, Maryland

[16] Iancovici, M., Riley, M., Sadek, F., Simiu, E. (2003). Wind effects on high-rise buildings: Database-assisted design versus the high-frequency force-balance technique. Eleventh Conference on Wind Engineering, Lubbock, TX, pg. 276-283

[17]Diniz, S., Iancovici, M., Fritz, W., Riley, M., Simiu, E. (2004). Probabilistic Performance Criteria for Tall Buildings Subjected to Wind Loads. Wind and Seismic Effects, Proceedings of the $36^{\text {th }}$ US-Japan Joint Panel Meeting, NIST Special Publication 1027, pg. 157-162.

[18] Main, J. A., and Fritz, W. P. (2006). Database-Assisted Design for Wind: Concepts, Software, and Examples for Rigid and Flexible Buildings. Gaithersburg, MD, USA: NIST Building Science Series 180, NIST.

[19] Simiu, E., Gabbai, R. D., and Fritz, W. P. (2008). Wind-induced tall building response: a time domain approach. Wind Struct. 11, 427-440.

[20] Yeo, D., Simiu, E. (2011). High-Rise Reinforced Concrete Structures: Database-Assisted Design for Wind. Journal of Structural Engineering, 137 1340-1349.

[21] Simiu, E. (2011). Design of Buildings for Wind, Second Ed., Wiley.

[22] Kwon, D.K., Kijewski-Correa, T., Kareem, A. (2008). E-analysis of high-rise buildings subjected to wind loads. Journal of Structural Engineering, 134:1139-53.

[23] Kareem, A., Kwon, D.K. (2017). A Cyber-Based Data-Enabled Virtual Organization for Wind Load Effects on Civil Infrastructures: VORTEX-Winds. Front. Built Environ. 3:48. doi: 10.3389/fbuil.2017.00048

[24] Wardlaw, R. L., Moss, G. F. (1971). A standard tall building model for the comparison of simulated natural winds in wind tunnels. Int. Conf. on Wind Effects on Buildings and Structures, Tokyo, 1245-1250.

[25]CNR-DT 207/2008 Report Consiglio Nazionale delle Ricerche, CNR - Commissione di studio per la predisposizione e l'analisi di norme tecniche relative alle costruzioni, Italy, 2008

[26] Vanmarcke, E. (2010). Random Fields. Analysis and Synthesis, World Scientific Publishing Co. Pte. Ltd.

[27] Lin, Y. K., Cai, G. (2004). Probabilistic Structural Dynamics: Advanced Theory and Applications. NewYork: McGraw-Hill

[28]Iancovici, M. (2019). Overview on the analysis and design of tall buildings to wind loads. Proceedings of the $2^{\text {nd }}$ National Conference on Wind Engineering (2NCWE2019), 6-7 June 2019, Bucharest

[29] Hatch, M., R. (2001). Vibration simulation using MATLAB and ANSYS, Chapman \& Hall/CRC, ISBN 1 58488205-0

[30]FEMA 356 (2000). Prestandard and Commentary for the Seismic Rehabilitation of Buildings, Federal Emergency Management Agency, American Society of Civil Engineers, Reston, Virginia

[31] Mathworks (2015). MATLAB. The Mathworks, Inc. Available at: http://www.mathworks.com/

[32]** Xtract (2015) TRC Bridge Design Software Inc. Available at: http://trcbridgedesignsoftware.com/ 